\title{
ANALYSIS OF ENGINES WITH MODULE DISCONNECTING OF CYLINDERS
}

\section{T.N. Kolesnikova, V. G. Zarenbin}

Regarded the constructions of automobile engines existed, in which the different processes of cylinder's disconnection take place. Found the disadvantages and pluses of engines with different methods of cylinder's disconnection. Marked that module engines have the highest fuel economy, but they are different with their ability to be more complex and unreliable construction. Also shown that in the crank-rocker engine without piston-rod has not only a possibility of increasing of effective Energy conversion efficiency because of low mechanical losses, where the module cylinder's disconnection is implemented more easily.

\section{В.И. Кубич, А.В. Юдиценко, Н.В. Блощинская ФЕНОМЕНОЛОГИЧЕСКИЙ ПОДХОД К ОЦЕНКЕ ТРИБОЛОГИЧЕСКОГО
СОСТОЯНИЯ СОПРЯЖЕНИЙ ЦПГ ДВС}

\begin{abstract}
Рассмотрены подходы к оченке обозначенных параметров трибологического состояния контакта поверхностей в сопряжениях «поршневое кольцо - гильза цилиндра», «поршень - гильза цилиндра» в начальный момент движения и мальх перемещениях с использованием эксплуатачионных натурных элементов конструкции на оборудовании машины СМЦ-2. При этом микропроцессы, происходящие на границе приповерхностных слоев материалов трибологических систем, рассматриваются как феномен. Представлены расширенные возможности разработанного программного продукта по моделированию тепломеханического нагружения контакта «гильза цилиндра - пориневое кольцо», позволяющие выполнять оченку диаметрального износа гильзы цилиндра на прогнозной наработке ДВС.
\end{abstract}

\section{Введение}

Решение научно-технических задач по обеспечению высокого уровня надежности трибосопряжений кривошипно-шатунного механизма ДВС при оптимизации тепломеханического нагружения, применение новых конструкционных материалов в условиях формирования поверхностных износостойких структур предполагают дальнейшую разработку и усовершенствование существующих методов определения износа рабочих поверхностей. Контактное взаимодействие поверхностей элементов сопряжений цилиндро-поршневой группы (ЦПГ) через формирующиеся смазочные слои при протекании рабочих процессов вследствие реализации термодинамического цикла в цилиндре двигателя предопределяет их трибологическое состояние. При этом неминуемо будут протекать сложные микропроцессы формирования и разрушения адгезионно-когезионных связей, адсорбционного взаимодействия между компонентами:

- на границах приповерхностных слоев материалов трибологических систем, например, «СЧ2444 - Lukoil-Super 15W40 - 4Х5МФ1С-Ш» для сопряжения «гильза-цилиндра - компрессионное кольцо», «СЧ24-44 - Lukoil-Super 15W40 - АК4-1» для сопряжения «гильза цилиндра - юбка поршня»;

- между многоатомными молекулами смазочного материала в присутствии поверхностноактивных веществ, метильными и метиленовими группами;

- например, между карбоксильными группами изомеров и активными центрами металлов.
Реальные эксплуатационные микропроцессы, которые происходят на границе приповерхностных слоев между компонентами каждой из трибологических систем, можно рассматривать, как некоторую «идеальную сущность - феномен, которая имеет непосредственную достоверность, и познать ее можно только интуитивно» [1]. Причем, познать их степень значимости для оценки трибологического состояния возможно не только выполняя моделирование характера и условий взаимодействия поверхностей на малогабаритных образцах, но и воспроизводя сам факт их проявления на эксплуатационных натурных образцах. Последнее представляется сложным, однако полученный результат будет более объективным и значимым для прогнозной оценки износа на любом из этапов изнашивания поверхностей трения. Исходя из приведенного, такой подход в оценке трибологического состояния сопряжений ЦПГ представляется как феноменологический, поскольку оценивается не сама «идеальная сущность», а факт ее проявления и влияния на оцениваемый параметр по форме, наиболее приближенной к эксплуатационной.

\section{Анализ ранее изданных публикаций}

Режимы смазки и трения, при которых протекают процессы взаимодействия элементов трибосопряжений цилиндро-поршневой группы (ЦПГ) двигателей внутреннего сгорания (ДВС), являются предметом научных дискуссий и исследований. В настоящее время обозначились три основных направления для оценки трибологического состояния рассматриваемых 
сопряжений [2]. Первое направление предполагает установление зависимости силы трения от нагрузки в зоне контакта $F_{\text {тр }}=f(N)$, что характерно для граничного режима трения $\lambda \leq 1$ [3]. Второе направление обусловлено тем, что сопряжение «поршневое кольцо - цилиндр» работает в жидкостном режиме трения (гидродинамический режим) $\lambda>3$. Это может рассматриваться как бесконтактное взаимодействие. Об этом свидетельствуют экспериментально измеренные значения толщины смазочного слоя между кольцом и цилиндром по ходу поршня, превышающие высоту микронеровностей поверхностей. Третье направление основывается на том, что наиболее вероятным режимом трения поршневых колец о цилиндр является переходный режим от смешанного $0<\lambda<3$ к граничному режиму смазки (не гидродинамический). В пользу этой точки зрения свидетельствует тот факт, что трение колец о цилиндр определяется не только вязкостью смазочного материала, а и характером проявления триботехнических свойств присадочных композиций. При этом проявляются эксплуатационные микрореологические свойства смазочных образований, которые отличаются градиентным распределением. Аналогичным образом можно представить изменение режимов смазки между поверхностями трения гильзы цилиндра и поршня. Принципиальными отличиями контактного взаимодействия в этом случае будут являться:

- характер механической напряженности в образующихся смазочных образованиях при уменьшении нагрузок со стороны колец;

- влияние упруго-пластического контакта на изменение напряжения сдвига во фрикционных контактах с учетом формирующегося «третьего тела» из компонентов материалов в граничных и приграничных контактных слоях.

В существующих моделях по определению интенсивности изнашивания кольца, гильзы, поршня применяются расчетные значения коэффициента трения, имеющего молекулярную и механическую составляющую [2,3]. При этом его численные значения не отображают реальное трибологическое состояние рассматриваемых сопряжений, обусловленное механическим, тепловым нагружением зон контактного взаимодействия через самоорганизуюшиеся смазочные слои.

Многофакторностью влияния на трибологическое состояние контакта деталей сопряжения «кольцо-гильза цилиндра» определен вид математической модели, которая позволяет получать рас- четные значения интенсивности изнашивания гильзы цилиндра в зависимости от угла поворота кривошипа. В соответствии с этим дается прогнозная оценка ее износа по пробегу автомобиля [4]. При этом данные о порядке математического соотношения учитываемых величин, определяющих связь пути трения верхнего поршневого кольца и пробега автомобиля во время работе двигателя на различных эксплуатационных режимах их использования, не приведены. Более того, открытым остается вопрос о возможности получения поверхности отклика для интенсивности изнашивания с одновременным учетом и частотного диапазона работы двигателя при компьютерном моделировании факторного пространства. Такой подход позволит давать более достоверную и объективную оценку закономерностям изнашивания контактируемых поверхностей с учетом установившихся и неустановившихся эксплуатационных режимов нагружения по мере израсходования ресурса до некоторого предельного технического состояния.

Цель исследования и постановка задачи

Целью работы представляется разработка методического обеспечения экспериментальных исследований параметров трибологического состояния взаимодействия поверхностей элементов натурных эксплуатационных трибосопряжений «гильза-цилиндра - компрессионное кольцо», «гильза цилиндра - юбка поршня» через смазочные слои для расширения возможностей программного обеспечения на базе существующей математической модели для прогнозной оценки интенсивности изнашивания и износа гильзы цилиндра.

Для достижения обозначенной цели необходимо:

- выполнить анализ технологических возможностей стационарной машины испытания материалов на трение и износ модели СМЦ-2;

- разработать и изготовить дополнительную оснастку для установки натурных эксплуатационных цилиндро-поршневых групп с приводом подвижного звена на вал машины трения;

- определиться с параметрами оценки трибологического состояния взаимодействия рассматриваемых поверхностей трения, опираясь на выражения, используемые в прототипной математической модели;

- определить возможные моделируемые условия теплового и механического нагружения зон контакта поверхностей трения;

- реализовать программный продукт на базе прототипной математической модели с расширенными функциональными возможностями. 


\section{Изложение основного материала исследо- вания и его обсуждение}

Анализ технологических возможностей стационарной машины СМЦ-2 показал следующее. В соответствии с габаритными размерами цилиндропоршневых групп, диаметр цилиндра $d_{\max }=120 \mathrm{Mм}$; длина гильзы цилиндра $l_{\max }=300$ мм, имеется возможность для неподвижного закрепления сборочной единицы ЦПГ без шатуна на верхней площадке корпуса нагружающего устройства. Для этого необходимо дополнительно применить стремянку фиксации гильзы и ее опорный кронштейн, к которому с помощью болтового соединения будет притягиваться корпус стремянки, прижимая к опоре машины исследуемую ЦПГ. Для использования датчика сопротивления перемещению на нижний приводной вал необходимо дополнительно установить переходную втулку с маховиком. Тогда, при использовании связи между пальцем поршня и маховиком в виде тросового соединения, возможно фиксировать сопротивление движению поршня с кольцами по поверхности гильзы цилиндра. Схема компоновки приведенных элементов приведена на рис.1.

Анализ схемы контактного взаимодействия элементов системы, нагружающих поверхность гильзы цилиндра, рис.2, а также математическое выражение, используемое для определения текущего значения коэффициента трения в прототипной модели, позволил сделать заключение о следующем.

В качестве параметров оценки трибологического состояния на данном этапе исследования необходимо рассматривать: сдвиговое сопротивле- ние молекулярной связи двух поверхностей, $\tau_{0}$; пьезокоэффициент молекулярной составляющей, $\beta$; молекулярную и механическую составляющие суммарного коэффициента трения при перемещениях с малыми скоростями движения. Причем сдвиговое сопротивление через граничные смазочные образования $6,8,9$, рис.2, определятся с учетом измеряемой силы трения покоя и геометрии контакта нагружающих элементов. Используя же неравномерность износа гильзы по длине хода поршня, возможно изменение значений удельных давлений колец при трении, что обусловит определение значения пьезокоэффициента. Изменяя условия контакта поверхностей за счет линейного расширения металлов при общем нагревании сборочной единицы нагревательным элементом 4, рис.1, и внося в зоны трения компоненты смазочного материала, обуславливается возможность определения обозначенных параметров уже с учетом объемных смазочных образований. Причем моделируемые условия механического нагружения определятся силами упругости поршневых колец и имитируемой нагрузкой на юбку поршня, а тепловое нагружение, как приведено выше, нагревательным элементом. Температурный режим может находиться в пределах от $-5^{\circ} \mathrm{C}$ до $120^{\circ} \mathrm{C}$.

В соответствии с математической моделью [4] реализован программный продукт с использованием языка программирования $\mathrm{C}++$ с дополнительным использованием библиотек Qt. Окна программного продукта приведены на рис.3. В качестве среды разработки использовался Qt Creator версии 5.5 .

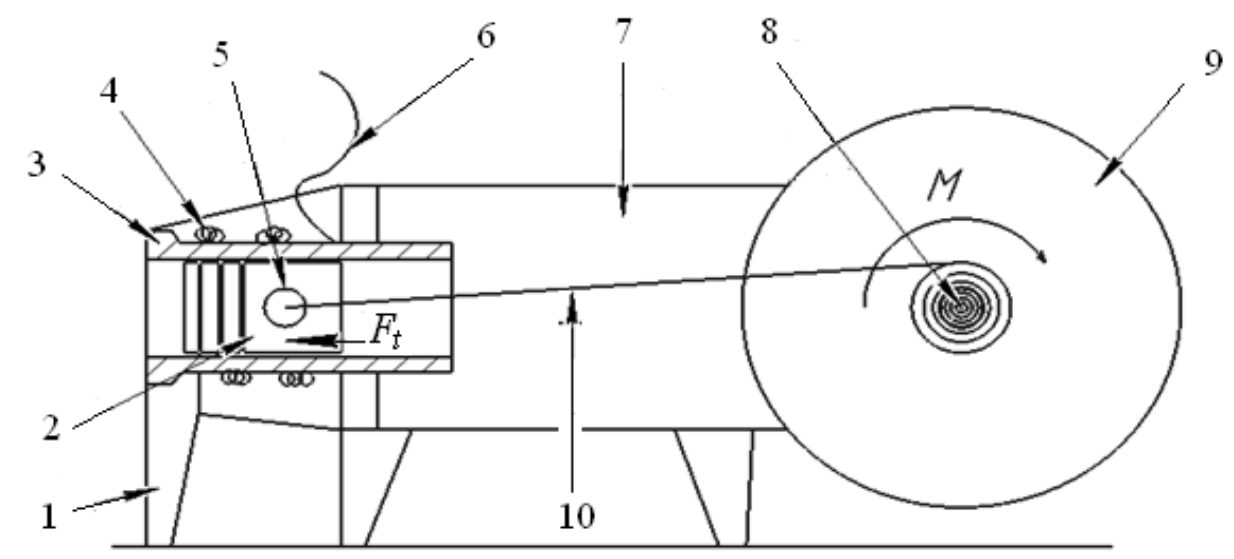

Рис.1. Схема установки натурной эксплуатаџионной ЦПГ на станине машины модели СМЦ-2.

1 - станина; 2 - поршень в сборе с кольиами и пальцем; 3 - гильза; 4 - нагревательньй элемент; 5 - палеи; 6 - провод термопары; 7 - корпус машины; 8 - вал машины; 9 - шкив; 10 - трос 


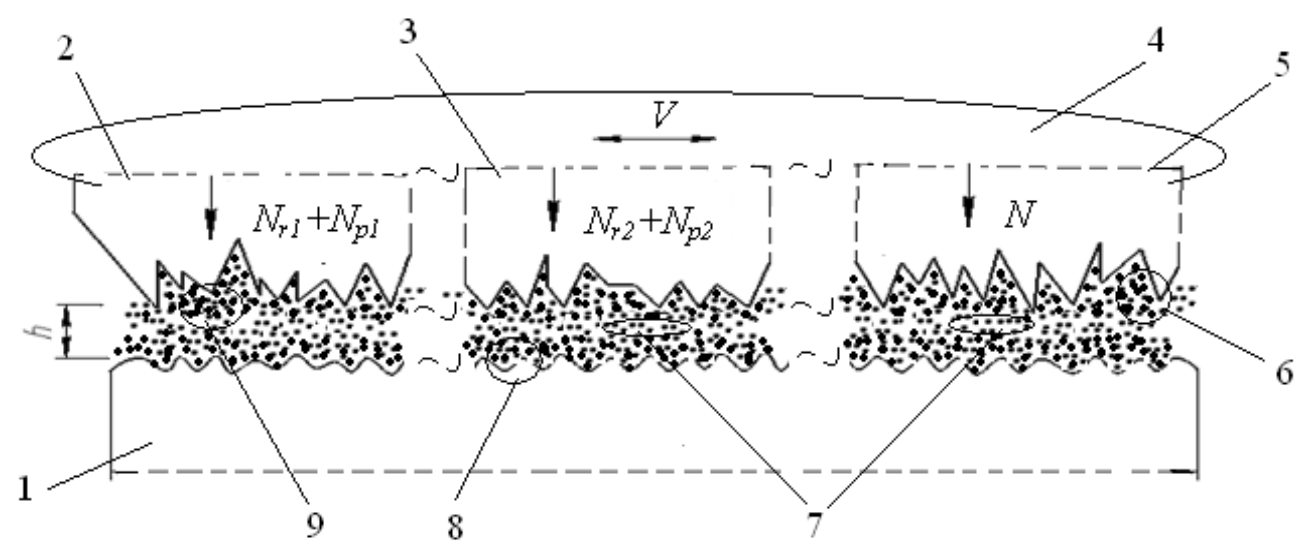

Рис.2. Схема комплексного контактного взаимодействия фрагментов микропрофилей поверхностей элементов ЦПГ через смазочные образования:

1 - гильза цилиндра; 2 - первое компрессионное кольцо; 3 - второе компрессионное кольцо; 4 - система нагружающих элементов; 5 - юбка поршня; 6,8,9 - граничные смазочные образования; 7 - смазочная среда объемного взаимодействия; $N_{r 1}, N_{r 2}$ - радиальная сила упругости колец, $H ; N_{p 1}, N_{p 2}$ - радиальная сила давления газов, $H$; $N$ - нормальная сила, $H$

Отличительной чертой в составленном алгоритме расчета является:

- выбор одного из условий контактирования [5]: «жесткая сфера внедряется в упругое полупространство» и «жесткая сфера внедряется в пластическое полупространство». Последнее условие характерно для трибофизических процессов, протекающих в сопряжении при использовании структур с низкими сопротивлениями сдвига, например при формировании смазочных образований (структурированные слои ионов металлов) из присадочных композиций в моторные масла [6], а также при формировании пленок из меди на поверхности гильзы [7];

- выбор расчета диаметрального износа в соответствии с обобщенным скоростным режимом работы ЦПГ и при долевом выражении наработок изделия на соответствующей частоте вращения коленчатого вала, имеющей вероятностный характер изменения.

Диаметральный износ $\Delta_{D}$ (мкм) гильзы цилиндра предлагается определять в соответствии с обобщенным по скоростному режиму работы ЦПГ выражением (1)

$\Delta_{D}=I_{i} \cdot L_{\mathrm{tp}}=I_{i} \cdot 0,036\left[L-h_{\mathrm{BK}}-\frac{L}{180}\left(\varphi_{\min }-180\right)\right] \cdot n \cdot T_{m}(1)$

где $I_{i}$ - интенсивность изнашивания гильзы цилиндра, рассчитанная в соответствии с предложенной в работе [4] математической моделью, при этом используется значение для соответствующего сечения гильзы (і - й угол поворота кривошипа); $L_{m p}$ путь трения верхнего поршневого кольца, мм; $n$ частота вращения коленчатого вала двигателя, мин $^{-1}$. Для расчета используется численное значе- ние двойственного содержания. С одной стороны это значение, при котором производится динамический расчет двигателя, и определяются значения нормальной силы $N$. С другой стороны - это усредненная частота, характерная для основного времени использования по назначению изделия. Например, в модели эксплуатации дизеля грузового автомобиля в городских условиях $n_{c p}=0,47 n_{н}$ в модели эксплуатации дизеля зерноуборочного комбайна $n_{c p}=0,79 n_{H}$, в модели эксплуатации дизелей сельскохозяйственных колесных и гусеничных тракторов $n_{c p}=0,9 n_{H}[8] ; h_{\varepsilon \kappa}$ - расстояние от торца поршня до первого компрессионного кольца, м; $T_{m}$ - прогнозная наработка, при которой оценивается диаметральный износ, мин. Прогнозируемая величина наработки может пересчитываться в условные тыс.км пробега, в соответствии с принятой методикой. Например, для легкового автомобиля 1 моточас $=25$ км; $L$ - значение хода поршня цилиндра двигателя соответствующего изделия: автомобиль; трактор; комбайн и др, мм; $\varphi_{\min }$ - значение угла поворота кривошипа при последнем значении минимальной интенсивности изнашивания (в соответствии с графическими расчетными зависимостями). Например, для представленной в работе [4] графической зависимости $\varphi_{\min }=244^{\circ}$.

Так, для двигателя с исходными параметрами (рис.1 а) для условия контактирования «жесткая сфера внедряется в упругое полупространство» прогнозные диаметральные износы гильзы цилиндра составляют:

- при $L_{m p}=0,036 \mathrm{м} ; \mathrm{n}=3600$ мин $^{-1} ; T_{m}=720000$ мото-мин $\quad(300000 \quad$ км пробега $) ; \quad I_{i}=2,1 \cdot 10^{-10}$; $\Delta_{D}=705,4$ мкм - это очень жесткие условия работы деталей ЦПГ; 
- при $L_{m p}=0,036$ м; $\mathrm{n}=1850$ мин $^{-1} ; T_{m}=480000$ мото-мин $\quad\left(200000 \quad\right.$ км пробега); $I_{i}=2,1 \cdot 10^{-10}$; $\Delta_{D}=241,67$ мкм - это средние по загруженности и продолжительности условия работы ЦПГ.

При $L_{m p}=0,036$ м; $n=1260$ мин $^{-1} ; T_{m}=240000$ (100000 км пробега) мото-мин; $I_{i}=2,1 \cdot 10^{-11} ; \Delta_{D}=8,2$ мкм - это самые благоприятные условия работы ЦПГ.

$$
\Delta_{D}=0,036 \cdot 10^{6} L_{\mathrm{tp}} n_{\mathrm{H}} T_{m} \sum_{i=1}^{n} \alpha_{i} \beta_{i} I_{h_{i}}=0,036 \cdot 10^{6}\left[L-h_{\mathrm{BK}}-\frac{L}{180}\left(\varphi_{\min }^{I}-180\right)\right] n_{\mathrm{H}} T_{m} \sum_{i=1}^{n} \alpha_{i} \beta_{i} I_{h_{i}},
$$

где $\alpha_{i}$ - доля времени наработки $T_{m}$ на $i$ - м скоростном режиме, например $\alpha_{i}=0,1 ; 0,4 ; 0,2 ; 0,3$ на режимах $0,22 n_{H} ; 0,46 n_{H} ; 0,71 n_{H} ; 0,57 n_{n} ; \beta_{i}$ - доля частоты вращения коленчатого вала ДВС на соответствующем скоростном режиме; $n_{н}$ - номинальная частота вращения коленчатого вала двигателя, мин $^{-1} ; I_{h i}$ - долевая интенсивность изнашивания при соответствующей частоте вращения, соответственно на скоростных режимах $0,22 n_{H} ; 0,46 n_{H} ; 0,71 n_{H}$; $0,57 n_{\mu}$.

Помимо приведенных на рис.3 окон программного продукта, также есть возможность графического вывода расчетных зависимостей $I_{i}=f(\varphi)$ и $\Delta_{D}=f\left(T_{m}\right)$. Графические зависимости могут использоваться для анализа характера влияния геометрических параметров ЦПГ, механических свойств материалов деталей, параметров шероховатости кольца, параметров молекулярной связи двух поверхностей через смазочные образования на величину интенсивности изнашивания поверхности гильзы. Формируемые контактным взаимодействи-
Полученные результаты хорошо согласовываются как с эксплуатационными данными типовых двигателей семейства ЗМЗ, так и результатами, приведенными в работе [4]. С учетом долей работы ДВС на различных скоростных режимах и средней продолжительности времени работы на них диаметральный износ $\Delta_{D}$ (мкм) ппредлагается рассчитывать в соответствии с выражением (2)

ем смазочные образования рассматриваются как результат феномена, проявляющийся с различной функциональной эффективностью. При этом тонкие поверхностные слои толщиной от 1 до 15 мкм могут иметь различный градиент механических свойств по глубине, что предопределяется закономерностями формирования вторичных структур.

Наличие сведений о параметрах, характеризующих непосредственно трибологический контакт эксплуатационных поверхностей: определяет целесообразность использования значений уже не объемных, а поверхностных свойств материалов деталей; позволяет получать более объективный результат в пределах предложенного программного продукта. Открытым остается вопрос о возможности оценки интенсивности изнашивания смазочных образований при граничной смазке, когда параметры шероховатости не оказывают существенного влияния на нарушение сплошности полимолекулярных смазочных слоев.

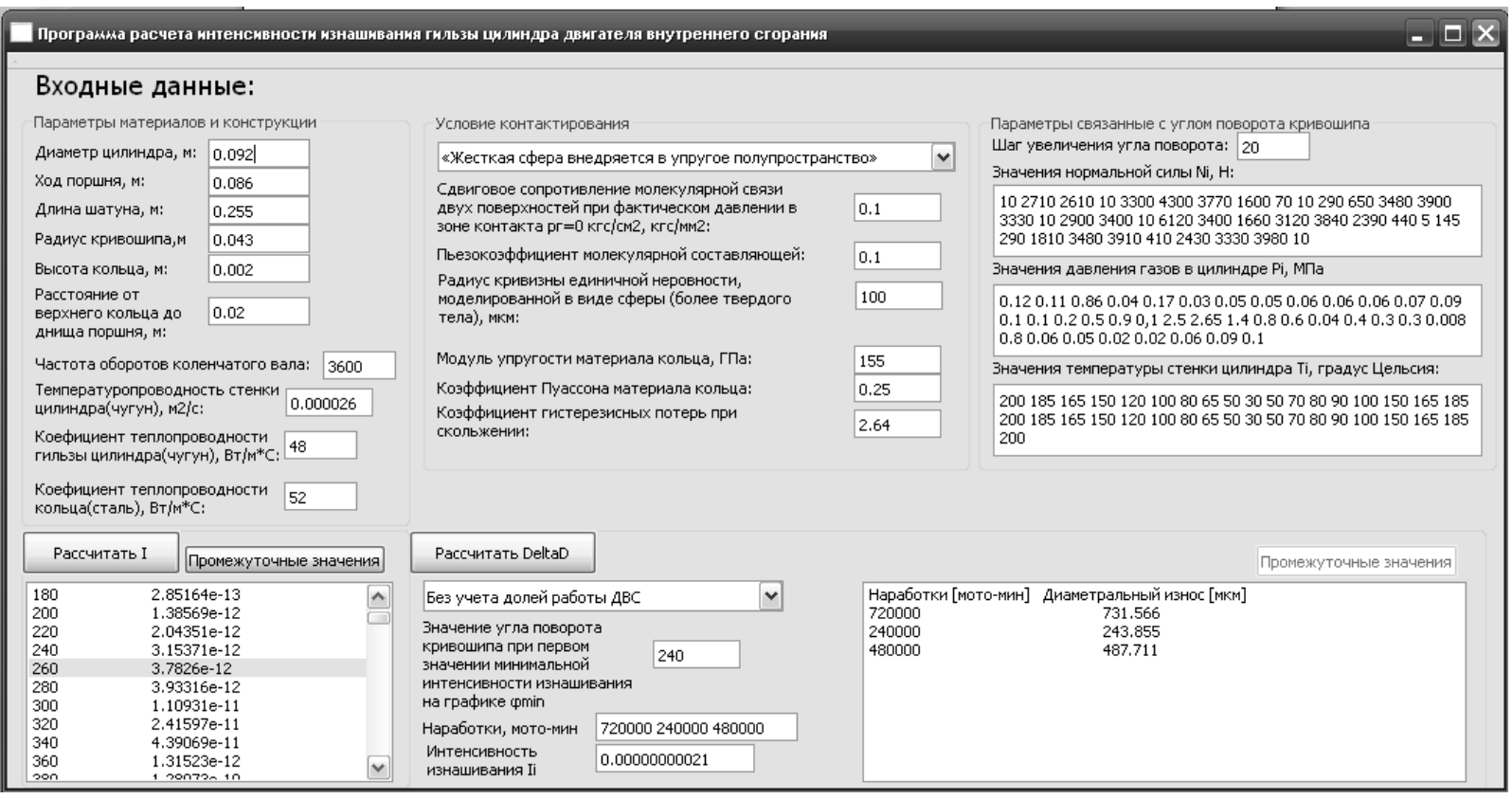

a) 


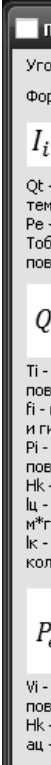

Прожежуточные данные

Угол поворота кривошипа $\mathrm{i}=80$

Формула расчета интенсивности изнашивания гильзы цилиндра:

$I_{i}=Q_{T_{i}} \cdot P_{e_{i}} \cdot T_{\text {об }} \quad$ Ii $=7.31904 \mathrm{e}-12$

Qt - безразмерный критерий, который характеризует

температурные условия на поверхности трения

Тоб - критерий, который характеризует нагрев контактных поверхностей при сгорании топлива в цилиндре

$Q_{T_{i}}=\frac{T_{i}{ }^{0.5} \cdot f_{i} \cdot\left(P_{i} \cdot 10^{-6}\right) \cdot H_{k}}{l_{\text {ц }}+l_{k}}$ 2ti $=6.25362 \mathrm{e}-15$

ті - температура стенки цилиндра в зависимости от і-того угла поворота кривошипа [градус Цельсия] Ті $=120$

ғі - козффициент трения между верхним компрессионным кольцом

и гильзой цилиндра в зависимости от угла поворота кривоши
Рі - давление Газов в Цилиндре в зависимости от і-того угла

Pi- - Аавление газов в цилиндре в за
поворота кривошипа [Па] $\mathrm{Pi}=0.17$

Hk- высота верхнего компрессионного кольца $[\mathrm{m}] \mathrm{Hk}=0.002$ І - коэффициент теплопроводности гильзы цилиндра [Вт]

$M^{*}$ градусцельсия] $[ц=48$

" козффициент теплопроводности вехнего компрессионного

$P_{e_{i}}=\frac{V_{i}^{0.1} \cdot H_{k}}{\alpha_{\text {ц }}}$ Pei $=101.771$

Уi - пинейная скорость, соответствующая i-тому углу

ПОвороТа кривошипа $[\mathrm{m} / \mathrm{c}]$

- высота верхнего компрессионного копьца [M] HK $=0.002$

- температуропроводность стенки цилиндра $\left[\mathrm{m}^{\wedge} 2 / \mathrm{c}\right]$ ац $=2.6 \mathrm{e}-05$

$\mathrm{T}_{\text {об }}=\frac{V_{P . T .}}{H_{k} \cdot S} \quad \mathrm{Tob}=11.5$

vpt - объем рабочего тела в цилинаре [ $\left[\mathrm{M}^{\wedge} 3\right]$

ного кольща $[\mathrm{m}] \mathrm{Hk}=0.002$

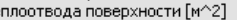

Условие контактирования - «жесткая сфера внедряется в упругое полупространство»

$$
f=\frac{2,6 \cdot\left(\tau_{0}\right) r^{0,67} \Theta^{0,67}}{N^{0,33}}+\beta+0,17 \alpha_{\mathrm{r}} \frac{N^{0,33} \Theta^{0,33}}{r^{0,67}}
$$

$\mathrm{fi}=0.167904$

т0 - САвиговое сопротивление молекулярной связи дву Х

поверхностей при фактическом давлении в зоне контакта рг $=0$ [кгс $\mathrm{CM} 2] \mathrm{T0}=0.1$

$\beta$ - пьезокоэффициент молекулярной составляющей $\beta=0.1$ радиускривизны единичной неровности, моделированной в виде сферы (более твердого тела) $r=100$
$\theta-$ обобщенная упругая составляющая $\theta=0.00604839$

\section{$\Theta=\frac{1-\mu^{2}}{E}$}

E - модуль упругости материала кольца [ГПа] $\mathrm{E}=155$

$\mu$ - козффициент Пуассона материала кольца $\mu=0.25$

or - козффиииент гистенезисеи потерль при скольжении аг $=2.64$

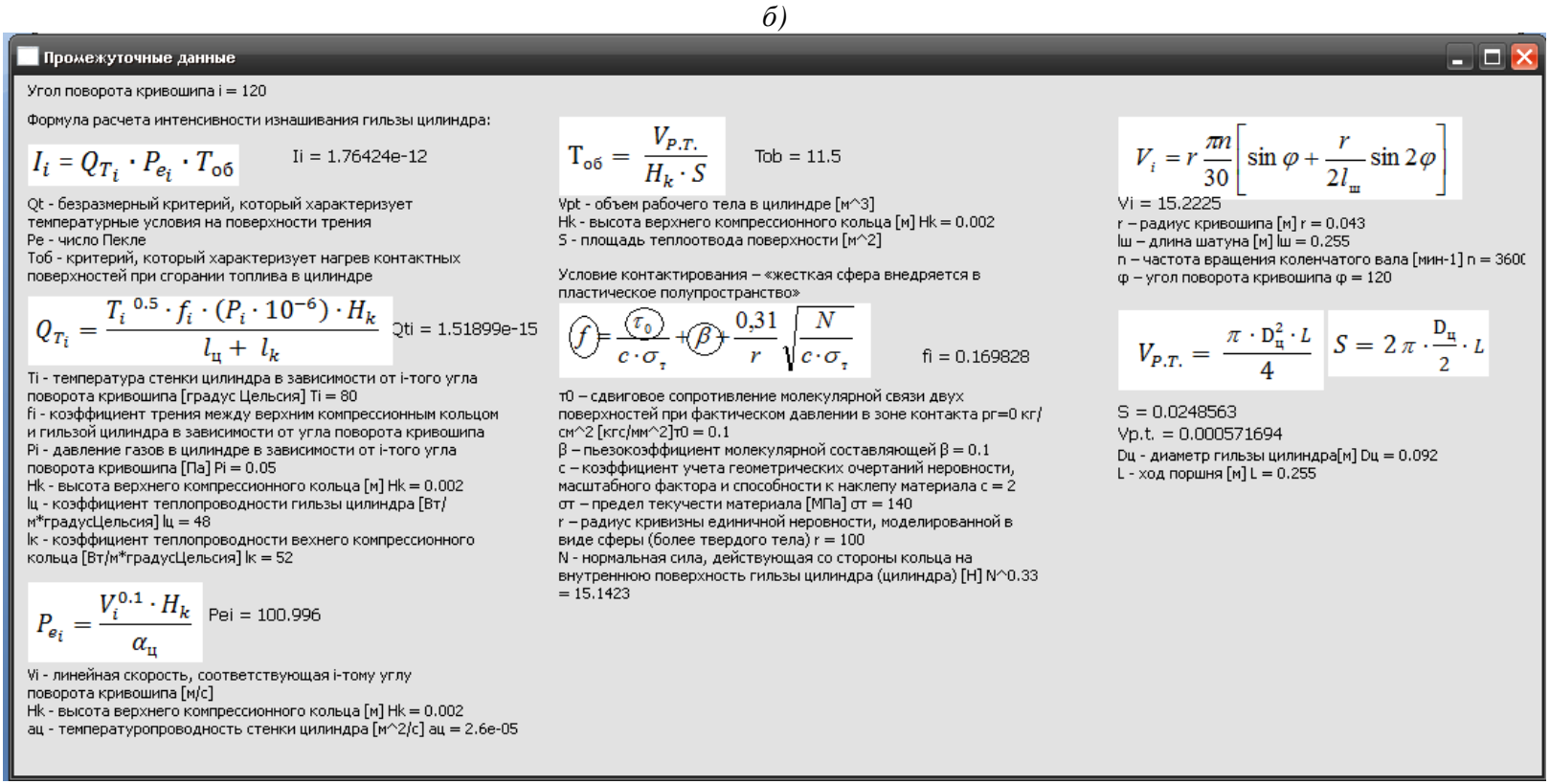

в)

Рис.3. Окна программного продукта:

a - стартовое окно для ввода исходных параметров и выбора условия контактирования; б - отображение промежуточных расчетов для условия контактировния «жесткая сфера внедряется в упругое полупространство»; в - отображение промежуточных расчетов для условия контактировния «жесткая сфера

внедряется в пластическое полупространство»

\section{Выводы}

Рассмотренные в работе подходы позволили для прогнозной оценки диаметрального износа гильзы цилиндра в соответствии с расширенными возможностями разработанного программного продукта по обозначенным параметрам трибологического состояния поверхностей трения предложить методику оценки взаимодействия элементов сопряжений натурных эксплуатационных ЦПГ в лабораторных условиях.

Для дальнейшего совершенствования предложенного программного продукта предлагается в соответствии с различными частотами вращения коленчатого вала ДВС, например $n_{l}-n_{5}$, разработать алгоритм формирования соответствующих массивов данных для значений сил, нагружающих гильзу цилиндра на различных этапах работы ЦПГ для конкретных условий взаимодействия поверхностей трения. Наличие зависимостей $I_{i}=f\left(\varphi_{i}\right)$ и соответствующих им рассчитанным износам предопределит с помощью программной среды формирование графически отображаемого многофакторного пространства, например $\Delta_{D}=f\left(n_{i}, T_{m}\right)$ для каждого сечения гильзы цилиндра, что представляется 
как направление дальнейших исследований.

\section{Список литературы:}

1. Феноменологический подход. Технический словарь [Электронный ресурс] - Режим доступа: http://www.ai08.org//. 2. Леванов И.Г. Экспериментальные исследования трибосопряжения «поршневое кольиоиилиндр» /И.Г. Леванов, И.В. Мухотров// Двигатели внутреннего сгорания. - 2012. - №2. - С.64-66. 3. Загайко С.A. Математическое моделирование изнашивания деталей ЦПГ ДВС/С.А Загайко//Уфа:УГАТУ. - 2013. -№3. С.231-238. 4. Микосянчик О.О. Моделювання інтенсивності зношування гільзи иіліндра двигуна внутрішнього згоряння /О.О. Микосянчик, Р.Г. Мнацаканов Р.Г., М.С. Хімко// Проблеми тертя та зношування. - НАУ.- 2015. 1(65). - С.140-145. 5. Крагельский И. В.Основы расчетов на трение и износ / И. В. Крагельский, М. Н. Добычин, В. С. Комбалов. М.: Машиностроение, 1977, - 526 с. 6. Ильин А. П. Влияние суспензии «моторное масло + смесь нанопорошков меди и никеля» на трибологические свойства пары трения «углеродистая сталь - низколегированная сталь» /А.П. Ильин, О.Б. Назаренко, С.В. Рихерт // Известия Томского политехнического университета, 2004. - Т. 307, - № 3. - С.77-79. 7. Салахутдинов И. Р. Повымение износостойкости гильз иилиндров бензиновых двигателей биметаллизачией рабочей поверхности трения / И.Р. Салахутдинов, А.Хохлов // Молодежный инновачионный форум Приволжского федерального округа. Конкурс научно-технического творчества молодежи (НТTМ), Ульяновск, 2015 г. [Электронный ресурс] - Режим доступа: http://ify.ulstu.ru. 8. Парсаданов И.В. Повышение качества и конкурентоспособности дизелей на основе комплексного топливно-экологического крите- рия: Монография/Парсаданов И.В. - Харьков НТУ «ХПИ». - 2003. - 244 c.

\section{Bibliographv (transliterated):}

1. Fenomenologicheskij podhod. Tehnicheskij slovar' [Phenomenological approach. Technical dictionary], available at: http://www.ai08.org. 2. Levanov, I.G., Muhotrov, I.V. (2012), "Jeksperimental'nye issledovanija tribosoprjazhenija "porshnevoe kol'cocilindr"'" [Experimental researches of interface"piston ringcylinder"], Dvigateli vnutrennego sgoranija, №2, pp. 64-66. 3. Zagajko, S.A., (2013), "Matematicheskoe modelirovanie iznashivanija detalej CPG DVS" [Mathematical design of wear of details of CPG ICE], Ufa:UGATU, №3, pp. 231-238. 4. Mykosyanchyk, O.O., Mnatsakanov, R.H., Khimko, M.S. (2015), "Modelyuvannya intensyvnosti znoshuvannya hil'zy tsilindra dvyhuna vnutrishn'oho z'horyannya" [Design of intensity of wear of shell of cylinder engine of internal combustion], Problemy tertya ta znoshuvannya, 1(65), pp.140-145. 5. Kragel'skij, I. V., Dobychin, M. N., Kombalov, V. S., (1977), "Osnovy raschetov na trenie i iznos" [Bases of calculations on a friction and wear], M., Mashinostroenie, pp. 526. 6. Il'in, A. P., Nazarenko, O.B., Rihert, S.V. (2004), "Vlijanie suspenzii "motornoe maslo + smes' nanoporoshkov medi i nikelja" na tribologicheskie svojstva pary trenija "uglerodistaja stal' - nizkolegirovannaja stal"'" [Influence of suspension "motor oil + mixture of nanopowders of copper and nickel" on tribology properties of pair of friction "carbon steel is low-alloy steel"], Izvestija Tomskogo politehnicheskogo univer-siteta, T. 307, № 3, pp. 77-79. 7. Salahutdinov, I.R., (2015), "Povyshenie iznosostojkosti gil'z cilindrov benzinovyh dvigatelej bimetallizaciej rabochej poverhnosti trenija" [Increase of wearproofness of shells of cylinders of petrol engines of by double metallization of working surface of friction], available at: http://ify.ulstu.ru. 8. Parsadanov, I. (2003), "Povyshenie kachestva $i$ konku-rentosposobnosti dizeliv na osnove kompleksnogo toplivnojekologicheskogo kriterija: Monografija" [Upgrading and competitiveness of diesels on the basis of complex fuel-ecological criterion: Monograph], Har'kov NTU «HPI», 244 p.

Поступила в редакиию 18.05.2016 2.

Кубич Вадим Иванович - канд. техн. наук, доцент, доцент кафедры автомобилей, Запорожский национальный технический университет, Украина, e-mail: reibung1 @ mail.ru, (061) 7642647

Юдиценко Артем Викторович - студент 4 курса кафедры «Двигатели внутреннего сгорания» транспортного факультету Запорожского национального технического университета, Украина, e-mail: artemv123@yandex.ru, (061) 7698241

Блощинская Наталия Викторовна - студентка 4 курса кафедры «Программных средств» факультета компьютерных наук и технологий Запорожского национального технического университета, Украина, e-mail: lovelykira@gmail.com, (061) 7643361

\section{ФЕНОМЕНОЛОГІЧНИЙ ПІДХІД ДО ОЦІНКИ ТРИБОЛОГІЧНОГО СТАНУ СПРЯЖЕНЬ ЦПГ ДВЗ}

\section{В.І. Кубіч, А.В. Юдіценко, Н.В. Блоцинська}

Розглянуто підходи до оцінки позначених параметрів трибологічного стану контакту поверхонь в 3'єднаннях «поршневі кільця - гільза циліндра», «поверхня поршня - гільза циліндра» в початковий момент руху і малих переміщеннях з використанням експлуатаційних натурних елементів конструкції на обладнанні машини СМЦ-2. При цьому мікропроцеси, що відбуваються на границі приповерхневих шарів матеріалів трибологічних систем, розглядаються як феномен. Представлені розширені можливості розробленого програмного продукту з моделювання тепломеханічного навантаження контакту «гільза циліндра - поршневе кільце», що дозволяють виконувати оцінку діаметрального зносу гільзи циліндра на прогнозному напрацюванні ДВЗ.

\section{PHENOMENOLOGICAL APPROACH TO THE EVALUATION OF THE CONDITION OF TRIBOLOGICAL PAIRINGS OF PISTON ICE}

\section{V.I. Kubich, A.V. Yuditsenko, N.V. Bloschinskaya}

Approaches to the evaluation of tribological contact status settings marked surfaces in up "piston ring-cylinder liner", "piston-cylinder liner" the starting point of the movement and small movements using operational full-scale structural elements on the hardware of the machine SMC-2. In this micro-processes that occur at the boundary surface layers of tribological systems, materials, considered as a phenomenon. Presented developed advanced software for modeling of thermal and mechanical loading contact "cylinder liner - piston ring" that enable you to estimate the diametrical wear of the cylinder liner to the target operating time of the internal combustion engine. 